\title{
Study on Influence of Mobile Phone Medium-based Sports Information on College Students' Sports Value
}

\author{
Duan Jingyu \\ Wuchang Institute of Technology 430065
}

\begin{abstract}
In the New Media Era, mobile phone medium has already gained momentum and is widely used in sports media. The integrated development of mobile phone medium and sports information has contributed to more widely and faster dissemination of sports information. In fact, mobile phone medium plays an important role in disseminating sports information and it is currently a key tool for college students to get sports information. The study of sports information dissemination through mobile phone medium tells the importance of mobile phone medium in disseminating sports information among leading college students and how the integration of mobile phone medium and sports information, to some extent, influence college students' sports value and lifestyles. Thus, this paper further analyzes the influence of mobile phone medium-based sports information to college students' sports value and sports lives in hope of helping them establish right sports consciousness and values.
\end{abstract}

Keywords—Mobile phone medium; Sports information; College students; Sports value

\section{INTRODUCTION}

With fast development of the Internet Information Technology, the number of mobile internet users among college students in China is increasing with the coverage rate of over $90 \%$ in 2015 based on the statistics of national survey on Internet users among college students conducted by China Internet Network Information Center. The current leading college students are born after 1990 . They are very curious to new things and can better accept them. They have strong desire for new media products and thus there are many new media users among college students. Mobile phone medium is a new media with more outreach and has comparatively strong penetrability in most areas. Thus, it gradually become the leading media among college students. It becomes very popular in colleges and universities and has a lot of fans. Compared with traditional media, it enjoys stronger timeliness and interactivity [1].

Sports culture is an important component in social cultural activities. It is closely related to our lives. With the increasing social civilization, it will become closer with news media. In modern society, excellent sports activities can attract more social members while news media provide more opportunities for those social members to watch sports events and to learn sports culture. In traditional media, social members mainly get sports information from sports magazines and periodicals to learn sports culture or participate in sports events. It fails to

Author Profile

Duan Jingyu, a femal from Han ethnic group, was born in January, 1978 in Wuhan, Hubei Province. She is an assistant professor on Science of Physical Education and Training at Wuchang Institute of Technology. present the audience the charm of sports in an all-round way. However, in the New Media Era, the integration of mobile phone medium and sports information not only promotes the dissemination of sports information but also enlarges the dissemination channels of sports information. Mobile phone is a popular network communication tool among modern college students and mobile phone media has already been widely used in various colleges and universities, which lays a good foundation for disseminating sports information. However, the current situation tells us that the advantage of mobile phone media in terms of disseminating sports information has not been fully displayed and its main potential in cultivating college students' sports value is yet to be tapped. It is now used more for entertainment instead of its publicity and education functions. Cultivating college students' sports quality should be the core requirements for disseminating sports information through mobile phone medium. In this way [2], the media function of mobile phones can be fully displayed and sports quality education in colleges or universities can become reality. As a result, this paper further analyzes influence of mobile phone medium-based sports information on college students' sports value and sports lives in hope of improving college students' sports quality.

\section{INTRODUCTION TO PARTICIPATION OF MOBILE PHONE MEDIA IN DISSEMINATION OF SPORTS INFORMATION}

\section{A. Current Situation of Participation of Mobile Phone Medium in Dissemination of Sports Information}

With the fast development of Internet network information society, people are more dependent on mobile phone medium. According to statistics on related surveys, currently many college students use mobile phones in their study and lives. On one hand, mobile phone brings convenience to them. On the other hand, it exerts much negative influence on them. For example, students may play games on mobile phones, which can harm their study. Some may watch movies or listen to music in class where they should have focused on study. Some even watch porn videos on mobile phones, which can bring harm to their mental and physical health. Although mobile phone medium can do various harms to college students, from macro perspective [3], it still has merits. Therefore, we should further digging its advantages and enhance its integration with sports information.

At present, we are getting to the New Media Era where mobile phone medium has gradually marched into sports 
industry and has given a major push to the development of sports media. Dissemination of many sports events or information were done through mobile phone medium. Due to the uncertainty of sports information in various sports events, we should give great attention to the timeliness of information related with the events. The audience deserves information on the events within a very short time while the traditional network media is not fast and convenient enough. To compensate this, mobile phone medium is widely used for the dissemination of sports information to improve the timeliness and convenience of sports media.

\section{B. Advantages of Participation of Mobile Phone Medium in Dissemination of Sports Information}

The statistics from surveys on mobile phone network users among college students in China shows that $90 \%$ of college students use mobile network. This is great opportunity for mobile phone medium in participating in disseminating sports information. Mobile phone medium will become the major medium for disseminating sports information. To be specific, mobile phone medium has the following advantages in disseminating sports information [4].

Firstly, it will break time and space limits in disseminating sports information. The traditional way to disseminate sports information is mainly through videos on the Internet. People need a television or computer to watch sports events and it has to be at a certain spot and period. However, mobile phone medium enables us to watch real-time sports events whenever and wherever we want. Besides, a mobile phone is small and light, thus it is easier to carry around.

Secondly, to use smart mobile terminal as a medium for sports media allows quantity data flow when disseminating the sports information and can obtain sports information at any time with fast information flow. This is why many college students often use mobile phone medium as the main tool to get sports information. They use smart mobile network to have access to sports information without the limitations on traditional sports media.

Thirdly, under the backdrop of the New Media Era, mobile phone medium can better cater to the personalized needs of targeted audience. Compared with televisions, mobile phones offer more choices. The audience can select the sports information freely and screen out the ones that are not needed. By doing so, college students enjoy sports information service with better quality. Nowadays, sports information is swarming in in large quantity [5]. Only twitting sports information based on personal interest can satisfy college students' specific needs so that they can select those that are useful to them. They can learn professional skills or theories with regard to sports practices and get to know sports requisites.

\section{Limits on Participation of Mobile Phone Medium in Disseminating Sports Information}

Despite of all the advantages of mobile phone medium in disseminating sports information, there are some comparatively big limits. Firstly, smart mobile terminal is required for disseminating sports information. The current smart phone usually has a small screen which cannot guarantee the audience a good visual experience. Secondly, the screen resolution of many smart phones is relatively poor and cannot meet our requirements [6]. The displaying of some big sports events in particular is not clear and thus gives us a poor visual experience. Lastly, playing sports games on smart phones requires large quantity of data flow and thus will be expensive. Some college students cannot bear such cost. Meanwhile, the instable connection to the network also ruins the audience's experience. Of coure, with the fast development of mobile phones and Internet information technology, mobile phone medium will have a more extensive space for development.

\section{INFLUENCE OF MOBILE PHONE MEDIUM- BASED SPORTS INFORMATION ON COLLEGE STUDENTS' SPORTS VALUE}

\section{A. Positive Influence}

1) Mobile phone medium-based sports information can change the sports value and sports behavior of college students.

According to related surveys, $60 \%$ of college students believe that mobile phone medium can help deepen their knowledge on sports information while $30 \%$ think that mobile phone medium can help benefit their study, entertainment and lives while only a small fraction of students get sports information on mobile phones out of pure interest.

During some Olympic Games, most students stay up all night or skip classes to watch live broadcasting of major sports games. This will definitely take a toll on their lives and studies. With the participation of mobile phone medium in disseminating sports information, many college students' attitude and way of thinking toward sports broadcasting have changed and their sports values, to certain extent [7], has been reshaped correctively. They think of watching sports events as an activity to relax during spare time. Many sports information is hard to obtain from class and such information and knowledge can only be obtained through mobile phones. Such information enables students to enjoy the successful experience, learn to unite and coordinate with others, and cultivate a consciousness of unremitting efforts and competition. Based on long-term accumulation of sports knowledge, students are given education on sports consciousness, their interest for sports activities grows, they can better participate in sports practices, select healthy way of living and correct sports values, which plays a vital role in promoting the healthy growth of students both mentally and physically. 
2) Mobile phone medium-based sports information can guide college students to select suitable sports activities.

Currently, there are various choices on college sports activities. These activities have relatively high requirements on the body conditions and hardware environment for students. Therefore, disseminating sports information through mobile phone medium can help students narrow down the sports activities that suit them. Scientific and reasonable sports practice not only helps build up our body but also get us relaxed both mentally and physically [8]. Students can collect sports knowledge and techniques related to sports practices through mobile phone medium. In doing so, mobile phone medium guides students to practice sports. It helps to improve their comprehensive quality and promote their interest in sports as well.

3) Mobile phone medium-based sports information can help college students to get into the habit of practicing sports.

Smart phone has become popular among college students. Its functions are being improved constantly along with the upgrading of mobile phone medium. The variety of sports information on mobile phone are richer [9], providing more options for college students on sports information, thus, better catering to their personalized needs. Meanwhile, more sports apps will appear on smart phones. Everyday, these apps will update sports information at a fixed time and give sports guidance in accordance with students' body conditions. They can also supervise students' routine sports activities and make corresponding practice plans. For instance, students who want to keep a nice body shape can download a professional body shaping app and practice sports in accordance with the plan the app makes [10]. They can even share their thoughts on the practice with their classmates to promote their enthusiasm in sports and get into the habit of practicing sports on the long run. Besides, through mobile phone medium, people can realize two-way communication and people of the same interest can establish an information sharing platform where all members can exchange their experiences and thoughts. They can even start a supervisory relationship with one other.

\section{B. Negative Influence}

Due to its interactivity, new media can provide a rich variety of sports information to college students and broaden their vision. However, the plural interactivity of mobile phone medium also has negative influence on them. To be specific, firstly, while passing on sports information during daily lives through mobile phone medium, college students may have less opportunities to participate in actual sports activities due to sports culture difference. Secondly, there may be many false reports or sports rumors on mobile phone medium that can lead college students to make wrong judgement on sports cultures. Thirdly, there are lots of negative news among sports information on mobile phones, including sportsmen taking stimulants, a report of a corrupted referee or match-fixing scandals. All those illegitimate sports behaviors will have a negative impact on college students' sports value.

\section{CONCLUSIONS}

Above all, mobile phone medium-based sports information has both positive and negative influence on college students' sports value. As a result, when mobile phones are used to disseminating sports information in colleges or universities, make sure the work ethic of seeking truth from facts is observed and guide students to establish correct sports value and improve their sports quality.

\section{REFERENCES}

[1] Yu Chunyan. A Study on Influence of Mobile Phone Medium-based Sports Information on College Students' Sports Lifestyles and Coping Strategies in the Journal of Educational Psychology 2011-2015. Journal of Technology Information, 2011,34, pp. 46+48.

[2] Guo Xiaowei. Analysis on Influence of Mobile Phone Medium-based Sports Information on College Students' Sports Practices in the Journal of Modern Sports Technology, 2016, 31, pp. 50-51.

[3] Chen Li, Hu Qilin. Influence of Mass Medium-based Sports Information on College Students in the Journal of Media, 2015, 10, pp.64-66.

[4] Yu Lin. Influence of Medium-based Sports Information on College Students' Participating in Sports Activities in the Journal of Modern Sports Technology, 2015, 25, pp.223+225.

[5] Li Nan. Studies on Influence of Sports information in New Media Era on Teenagers and its Dissemination Effects in the Journal of Teenager Sports, 2016, 02, pp.15-17.

[6] Li Man. Influence of Mobile Phone Medium-based Sports Information on College Students' Sports Lifestyles in the Journal of China Newspaper, 2016, 14, pp.39-40.

[7] Hou Li. Studies on Promoting Women College Students' Participating in Sports with New Media in the Journal of China School Physical Education(Higher Education). 2016 03, 22-25.

[8] Ye Chunyan, Wang Jingxian. Studies on Development of Sports Through Mobile Phone Medium in the Jourmal of Sports World(Scholarly), 2012, 01,4-6.

[9] Yi Haiyong. Survey and Analysis on Current Situation of College Students' Obtaining Sports Information in All Media Era in the Journal of Hubei Sports Technology, 2012, 05, pp.521-523.

[10] Chang Wei, Lv Shengli. Influence of Sports Information from Network on College Students Sports Lifestyles in the Journal of China Adult Education, 2010, 19, pp.150-151. 